\title{
FOSFOETANOLAMINA SINTÉTICA: ANÁLISE DE UM CASO CONTROVERSO \\ DE JUDICIALIZAÇÃO DO FORNECIMENTO DE MECIDAMENTO SEM COMPROVAÇÃO CIENTÍFICA
}

\section{PHOSPHOETHANOLAMINE SYNTHETIC: ANALYSIS OF A JUDICIALIZATION OF CONTROVERSIAL CASE DRUG SUPPLY WITHOUT PROOF SCIENTIFIC}

\author{
Tiago Antonio Paulosso Anibal ${ }^{1}$ \\ Juvêncio Borges Silva ${ }^{2}$
}

\section{RESUMO}

O objeto deste trabalho é a verificação da possibilidade do Judiciário acolher um pedido de fornecimento da substância fosfoetanolamina sintética. Por meio de uma revisão bibliográfica e jurisprudencial, observa-se que a judicialização de políticas públicas tem sido pacífica quando se trata de deferir pedidos de medicamentos, salvo na hipótese de ausência de certificação de eficácia terapêutica e segurança ao paciente, com o respectivo registro Agência Nacional de Vigilância Sanitária. Conclui-se pelo não acolhimento de pedido de fornecimento da fosfoetanolamina pelos tribunais em face da ausência de amparo jurídico e científico, devendo os tribunais decidir por critérios jurídicos, não políticos.

Palavras-chave: Judicialização, Políticas públicas, Fosfoetanolamina sintética, Anvisa

\begin{abstract}
The object of this work is to verify the possibility of the judiciary receive a request for supply of synthetic phosphoethanolamine substance. Through a bibliographical and jurisprudential review, notes that the legalization of public policy has been peaceful when it comes to grant requests for medications, except in the event of lack of therapeutic efficacy of accreditation and patient safety, with its Agency registration national Health Surveillance . It is concluded by no host application providing phosphoethanolamine by the courts due to the lack of legal and scientific support, and should the courts decide legal criteria, not political.
\end{abstract}

Keywords: Legalization, Public policy, Synthetic phosphoethanolamine, Anvisa

\footnotetext{
${ }^{1}$ Mestrando em Direitos Coletivos e Cidadania pela Universidade de Ribeirão Preto - UNAERP, São Paulo, (Brasil). E-mail: tapaanibal@ hotmail.com

${ }^{2}$ Pós - Doutorado em Direito pela Faculdade de Direito da Universidade de Coimbra - UC, Coimbra, Portugal. Docente e Líder do Grupo de Pesquisa Direitos Coletivos, Políticas Públicas e Cidadania pela Universidade de Ribeirão Preto - UNAERP, São Paulo, (Brasil). E-mail: juvborges@ netsite.com.br
} 


\section{INTRODUÇÃO}

A Constituição Federal de 1988 consagra os direitos e garantias fundamentais e, de igual forma, os direitos fundamentais sociais, competindo ao Estado garanti-los e efetivá-los em prol de toda a coletividade, mormente no que tange aos direitos prestacionais como saúde, educação, moradia, cuja característica própria é a imprescindibilidade de uma atuação estatal positiva. (SALLES, 2006, p. 177-191).

Como corolário dos direitos sociais é que emergem as políticas públicas, apontadas por Bucci como sendo "programas de ação governamental visando a coordenar os meios à disposição do Estado e as atividades privadas, para a realização de objetivos socialmente relevantes e politicamente determinados" (BUCCI, 2006, p. 241), ou, também, a atuação estatal, planejada e coordenada, no intuito de se alcançar os fins sociais previstos no Texto Constitucional.

Nada obstante, diariamente o Poder Judiciário é acionado para determinar à Administração Pública a implementação de direitos sociais que estejam sendo negligenciados, como ocorre frequentemente nas demandas judiciais postulatórias de fornecimento de medicamentos e insumos médicos (direito à saúde) $)^{3}$.

O debate nesta seara ganhou notoriedade no segundo semestre do ano de 2015, quando foi noticiada a substância fosfoetanolamina sintética, que seria capaz de combater o câncer em suas diversas formas.

Referida substância, estudada no Brasil há cerca de 20 (vinte) anos, não possui registro na Anvisa (Agência Nacional de Vigilância Sanitária), e sequer foi iniciado o procedimento administrativo para esse fim, sendo que, a despeito de ter sido distribuída gratuitamente nesse período, não há qualquer estudo cientifico realizado em seres humanos que tenha seguido os protocolos exigidos pela área científica para atestar sua eficácia. Nada obstante, tendo em vista a repercussão midiática em torno da referida substância, que teria o condão de combater de forma eficaz os efeitos deletérios do câncer, proporcionando melhoras significativas nos pacientes oncológicos que dela teriam feito uso, tal suscitou um clamor por parte de pacientes oncológicos e seus familiares no sentido de que tal substância lhes fosse disponibilizada, o que acabou levando à propositura de inúmeras ações judiciais propugnando pelo fornecimento da referida substância, ocasionando, destarte, na judicialização desta matéria. 
O presente artigo tem como escopo o estudo deste caso específico de judicialização, propondo-se a refletir sobre o fenômeno da judicialização das políticas públicas, para a seguir estabelecer um recorte epistemológico com vistas a analisar o caso da fosfoetanolamina e os desdobramentos do tratamento dado pelos tribunais às postulações com vistas ao seu fornecimento e, por fim, formular um entendimento a respeito da possibilidade de um magistrado determinar que o Estado providencie o seu fornecimento, não obstante a referida substância não ter sido devidamente regulamentada pela Anvisa.

Para o alcance deste desiderato, nortearemos a pesquisa pelo método analíticodedutivo, valendo-nos de publicações científicas, livros e revistas, bem como das publicações disponíveis na internet, além das jurisprudências que versam sobre esta matéria.

\section{JUDICIALIZAÇÃO DAS POLÍTICAS PÚBLICAS DE SAÚDE}

O termo "política", por si só, denota um programa de ação (COMPARATO, 1998, p. 44), isto é, a materialização, por meio de atos e normas, da proposta de governo formulada pelo então governante, ou ainda, segundo Dworkin (2002, p. 36):

[...] aquele tipo de padrão que estabelece um objetivo a ser alcançado, em geral uma melhoria em algum aspecto econômico, político ou social da comunidade, (ainda que certos objetivos sejam negativos pelo fato de estipularem que algum estado atual deve ser protegido contra mudanças adversas).

Por outro lado, a expressão "políticas públicas”, como se observa das lições de Canella Júnior (2001, p. 147), estar-se-ia a referir-se a "todos os atos legislativos e administrativos necessários à satisfação espontânea dos direitos fundamentais sociais", ou seja, o termo “públicas” representa a atuação do político direcionada à consecução da finalidade pública de interesse da coletividade.

\footnotetext{
${ }^{3}$ Cumpre esclarecer, desde já, que a expressão "ações de medicamentos", utilizada no decorrer do trabalho, referirse-á a demandas ajuizadas envolvendo pedidos de fornecimento de medicamentos, insumos médicos, além ainda de cirurgias, exames, dentre outros.
} 
Políticas públicas configuram decisões de caráter geral que apontam rumos e linhas estratégicas de atuação governamental, reduzindo os efeitos da descontinuidade administrativa e potencializando os recursos disponíveis ao tornarem públicas, expressas e acessíveis à população e aos formadores de opinião as intenções do governo no planejamento de programas, projetos e atividades (MINISTÉRIO DA SAÚDE: 2006).

Ana Paula de Barcellos (2008, p. 112), sustenta que “políticas públicas pode designar, de forma geral, a 'coordenação dos meios à disposição do Estado, harmonizando as atividades estatais e privadas para a realização de objetivos socialmente relevantes e politicamente determinados"”.

Nesse contexto, observa-se que o tema "políticas públicas"4 é claramente relacionado à função constitucionalmente prevista ao Estado-Administração, elas são "O Estado em ação", "o resultado da política institucional e processual" que "se materializam em diretrizes, programas, projetos e atividades que visam resolver problemas e demandas da sociedade" (SCHIMIDT, 2008, p. 2311), se constituindo em

[...] um complexo de processos destinados a formular e executar ações que implementem a funcionalização efetiva e concreta dos direitos fundamentais através de cometimentos constitucionalmente atribuídos, explícita ou implicitamente, obrigatória ou dispositivamente, ao sistema decisório juspolítico governança- administração da atuação do Estado em prol do indivíduo, tutelando e garantindo seus direitos humanos fundamentais (ABBOUD, 2014, p. 165).

Vale ressaltar que, além do seu objeto acima destacado, também é marcante nas políticas públicas o caráter da discricionariedade, presente tanto em sua discussão, como na sua elaboração execução.

[...] fala-se em discricionariedade quando a disciplina legal faz remanescer em proveito e a cargo do administrador uma certa esfera de liberdade, perante o quê caber-lhe-á preencher com seu juízo subjetivo, pessoal, o campo da indeterminação normativa, a fim de satisfazer no caso concreto a finalidade da lei (MELLO, 2007, p. 926).

Depreende-se, portanto, que as políticas públicas, como programa de ação que um administrador se propõe a realizar, com normas e atos, com vista a atingir a finalidade pública de tutelar os direitos fundamentais da coletividade, tem caráter complexo, marcado por situações nas quais há que se conceder ao administrador a possibilidade de juízos de conveniência e oportunidade, a despeito da existência de severas balizas intransponíveis ${ }^{5}$. 
Logo, na realização das políticas públicas, há que se respeitar o princípio da separação de poderes, aclamada por Montesquieu e acolhida pelos Estados ocidentais, que estabelece competências específicas para cada um dos poderes do Estado.

Por assim ser, é de fácil percepção que dentro de um contexto de Estado Democrático de Direito, cumpre ao Poder Judiciário dizer o direito, pautado então na lei, ou, mais precisamente, na Constituição Federal. Logo, impende ao julgador zelar para que haja o cumprimento das normas constitucionais e, ainda que sem lei infraconstitucional, faça a intermediação para com o indivíduo ${ }^{6}$.

Logo, os direitos humanos contidos na Constituição, ou por ela abrangidos, representam o parâmetro e o objetivo a serem alcançados pelo magistrado, cuidando ele de zelar para que em situações postas em debate no Judiciário prevaleça a garantia dos direitos fundamentais dos indivíduos.

Em se tratando dos direitos sociais, que se inserem na categoria de normas de eficácia limitada (SILVA, 2005), da subcategoria das programáticas ${ }^{7}$ (RAMOS, 2010), dependem, pois, do administrador para a consecução de seus teores, não se esquecendo que, em razão do princípio da estrita legalidade, haverá também, em muitas situações, a necessidade de ato provindo do legislador.

Nada obstante, a discussão levantada pela bandeira da lesão ao princípio da separação dos poderes já foi superada pelo Supremo Tribunal Federal quando do julgamento da ADPF $n^{\circ}$ 45, tendo o Ministro Celso de Melo pontuado no seguinte sentido:

[...] embora em bases excepcionais, poderá atribuir-se ao Poder Judiciário, se e quando os órgãos estatais competentes, por descumprirem os encargos político- jurídicos que sobre eles incidem, vierem a comprometer, com tal comportamento, a eficácia e a integridade de direitos individuais e/ou coletivos impregnados de estatura constitucional, ainda que derivados de cláusulas revestidas de conteúdo programático. ${ }^{8}$

\footnotetext{
${ }^{4}$ João Pedro Schmidth observa que a locução “políticas públicas” apresenta-se, na literatura, "de modo polissêmico e com contornos poucos definidos".

${ }^{5}$ A Constituição Federal de 1988 (marcada por arrolar uma série de direitos e garantias fundamentais) e a Lei de Responsabilidade Fiscal (fixa porcentagens mínimas de gastos) delineiam os direitos que o Estado deve atender, bem como o valor mínimo que se deve destacar para a sua consecução.

${ }^{6}$ Vale frisar o teor do artigo $5^{\circ}, \S 1^{\circ}$, da $\mathrm{CF} / 88$, no qual está assim expresso: “As normas definidoras dos direitos e garantias fundamentais têm aplicação imediata".
} 
Outrossim, também se suscita a tese da reserva do possível, a qual, de origem germânica, é trazida ao ordenamento jurídico brasileiro com uma conotação relacionada à disponibilidade de recursos públicos. Como observa Falsarella (2012) "na origem, quando em 1972 o Tribunal Constitucional Alemão pela primeira vez fez menção à expressão reserva do possível, utilizou-a no sentido de impor razoabilidade aos pleitos que o indivíduo fizesse em face do Estado". Neste sentido também observa Barcelos (2001, p. 276) que "a expressão reserva do possível procura identificar o fenômeno econômico da limitação dos recursos disponíveis diante das necessidades quase sempre infinitas a serem por eles supridas", ou como pontuado na $\mathrm{ADPF} \mathrm{n}^{\mathrm{o}} 45^{9}$,

[...] traduzem-se em um binômio que compreende, de um lado, (1) a razoabilidade da pretensão individual/social deduzida em face do Poder Público e, de outro, (2) a existência de disponibilidade financeira do Estado para tornar efetivas as prestações positivas dele reclamadas ${ }^{10}$.

Porém, tal arguição cede diante da invocação do denominado mínimo existencial, o qual representa, em síntese, as condições materiais básicas que estruturam/viabilizam uma vida humana com dignidade, conforme se confere:

\begin{abstract}
ADMINISTRATIVO - AÇÃO CIVIL PÚBLICA - CONTROLE JUDICIAL DE POLÍTICAS PÚBLICAS - POSSIBILIDADE EM CASOS EXCEPCIONAIS - DIREITO À SAÚDE - FORNECIMENTO DE EQUIPAMENTOS A HOSPITAL UNIVERSITÁRIO - MANIFESTA NECESSIDADE - OBRIGAÇÃO DO ESTADO - AUSÊNCIA DE VIOLAÇÃO DO PRINCÍPIO DA SEPARAÇÃO DOS PODERES - NÃOOPONIBILIDADE DA RESERVA DO POSSÍVEL AO MÍNIMO EXISTENCIAL. (...) 3. A partir da consolidação constitucional dos direitos sociais, a função estatal foi profundamente modificada, deixando de ser eminentemente legisladora em pró das liberdades públicas, para se tornar mais ativa com a missão de transformar a realidade social. Em decorrência, não só a administração pública recebeu a incumbência de criar e implementar políticas públicas necessárias à satisfação dos fins constitucionalmente delineados, como também, o Poder Judiciário teve sua margem de atuação ampliada, como forma de fiscalizar e velar pelo fiel cumprimento dos objetivos constitucionais. 4. Seria uma distorção pensar
\end{abstract}

\footnotetext{
${ }^{7}$ Enquanto as primeiras (de eficácia plena) sinalizam aquelas normas constitucionais aptas a, desde logo, produzirem seus efeitos, com aplicabilidade direta, imediata e integral, as segundas (de eficácia contida) são aptas também a já produzirem seus efeitos, em que pese possam futuramente ter seu alcance reduzido, e, por fim, as terceiras (limitada) são aquelas normas constitucionais que, para sua realização, dependem da execução de ato apenas por parte do legislador (preceptivas) ou, quando não, necessitam tanto de ato do legislador como do administrador (programáticas).

8 Disponível em http://www.sbdp.org.br/arquivos/material/343_204\%20ADPF\%202045.pdf. Acesso em 05/04/2016.

9 Disponível em http://www.sbdp.org.br/arquivos/material/343_204\%20ADPF\%202045.pdf. Acesso em 05/04/2016.
} 
que o princípio da separação dos poderes, originalmente concebido com o escopo de garantia dos direitos fundamentais, pudesse ser utilizado justamente como óbice à realização dos direitos sociais, igualmente fundamentais. Com efeito, a correta interpretação do referido princípio, em matéria de políticas públicas, deve ser a de utilizá-lo apenas para limitar a atuação do judiciário quando a administração pública atua dentro dos limites concedidos pela lei. Em casos excepcionais, quando a administração extrapola os limites da competência que lhe fora atribuída e age sem razão, ou fugindo da finalidade a qual estava vinculada, autorizado se encontra o Poder Judiciário a corrigir tal distorção restaurando a ordem jurídica violada.

(STJ - Segunda Turma, no Recurso Especial n. 1041197 - MS, rel. Ministro Humberto MARTINS). ${ }^{11}$

Vale observar que a noção de mínimo existencial, conceito este introduzido no direito pátrio por Ricardo Lobo Torres (1989), e muito bem analisado por Sarlet e Figueiredo (2007), distingue-se da ideia de piso vital mínimo, eis que, enquanto este traduz a garantia da vida humana, aquele se refere a uma vida com qualidade, isto é, não apenas a garantia da vida, mas que esta se desenvolva em condições dignas.

Dessa maneira, aqueles direitos que possuem fundamentação direta no princípio da dignidade da pessoa humana, e que constituam a essência do mínimo existencial, a exemplo da saúde, não podem ser suprimidos ou omitidos (não fornecidos), seja qual for o argumento, inclusive a reserva do possível, e sequer a própria alegação de discricionariedade. É o que afirma Abboud (2014, p. 168).

Dito de outro modo, não há opção para o Judiciário, Legislativo e Executivo em assegurar direito à saúde, educação básica e demais direitos fundamentais. Diante de um quadro de inércia da Administração, não há discricionariedade que impeça a concretização desses direitos fundamentais pelo Judiciário. $\mathrm{O}$ que não equivale a dizer que todo e qualquer direito pode ser buscado pelo Judiciário.

\footnotetext{
10 Trecho do voto do Ministro Celso de Mello, quando do julgamento da ADPF 45. De se observar que, a despeito da conotação minimalista a que fora imposta a teoria da reserva do possível, o ilustre julgador pontuou como baliza a razoabilidade do pleito em si, em complemento à análise que se deve fazer sobre a disponibilidade financeira, aproximando-se um pouco do teor original da teoria em questão.

11 Disponível em http://stj.jusbrasil.com.br/jurisprudencia/6909418/recurso-especial-resp-1041197-ms2008-

0059830-7. Acesso em 12.01.2016.
} 
Dessa maneira, o entendimento prevalecente é no sentido de que, consistindo em bem da vida, postulado em juízo abrangido pela noção de mínimo existencial, é viável ao Judiciário, caso acionado, ofertar uma resposta que aparentemente ${ }^{12}$ interfira na seara de outro Poder, ainda que reflita em políticas públicas, a exemplo das ações de medicamentos.

Tanto é assim que, atualmente, as ações com pedidos de fornecimento de medicamentos, insumos ou mesmo cirurgias, dentre outros, relacionados também à saúde, cujo número de demandas é exorbitante, bem como a cifra de valores gastos, aproximando-se cada vez mais do valor que se investe, pelas vias regulares, à implantação da política pública de saúde, tem sido atendidos pelo Poder Judiciário, não obstante estas decisões acabem por fazer com que sejam extrapolados os gastos previstos pelo administrador público.

Como observa Cambicroli (2015), no ano de 2013, apenas no Município de São Paulo foram ajuizadas 2.011 (duas mil e onze) demandas de medicamentos, sendo que tal volume importou num gasto municipal de $\mathrm{R} \$ 3.200 .000$ (três milhões e duzentos mil reais), enquanto que no ano de 2010 esse gasto foi de $\mathrm{R} \$ 2.600 .000$ (dois milhões e seiscentos mil reais).

Segundo Perrin (2015), no ano de 2014, foram ajuizadas (em todo o Estado) 14.383 ações de medicamentos em face do Estado de São Paulo, sendo que, no mesmo período, teria gasto cerca de $\mathrm{R} \$ 542$ milhões de reais em compras para cumprir decisões judiciais nestas demandas, muito embora - veja bem - tenha sido investido aproximadamente R \$ 1 bilhão na consecução da política pública de compra de medicamento e produtos médicos para atendimento ao público em geral.

Em face da notória e maciça jurisprudência acolhedora desses pedidos, há que se refletir a respeito deste quadro, ponderando sobre alternativas, e considerando algumas decisões do Judiciário, inclusive do Supremo Tribunal Federal, além de manifestações do Conselho Nacional de Justiça e da doutrina sobre esta matéria.

\footnotetext{
${ }^{12}$ Contudo, na verdade, tão apenas estará exercitando sua própria função, que é de resguardar e tutelar a dignidade da pessoa humana.
} 


\subsection{PONDERAMENTOS CORCENTENTES Às AÇÕES DE FORNECIMENTO DE MEDICAMENTOS}

Em abril e maio de 2009, o então presidente do Supremo Tribunal Federal (Ministro Gilmar Mendes) realizou audiência pública justamente para ouvir especialistas do assunto, além de advogados, promotores, juízes e gestores públicos para debater a matéria.

Muito embora dos encontros realizados não tenham sido formulados enunciados, posteriormente, quando do julgamento do Agravo Regimental no Agravo de Instrumento $\mathrm{n}^{\circ}$ 553.712/RS ${ }^{13}$, o Ministro Gilmar Mendes fez menções que sintetizam o entendimento decorrente dos debates.

[...] no Brasil, o problema talvez não seja de judicialização ou, em termos mais simples, de interferência do Poder Judiciário na criação e implementação de políticas públicas em matéria de saúde, pois o que ocorre, na quase totalidade dos casos, é apenas a determinação judicial do efetivo cumprimento de políticas públicas já existentes.

E assim prossegue:

[...] podemos concluir que em geral, deverá ser privilegiado o tratamento fornecido pelo SUS em detrimento de opção diversa escolhida pelo paciente, sempre que não for comprovada a ineficácia ou a importância da política de saúde existente.

Essa conclusão não afasta, contudo, a possibilidade de o Poder Judiciário, ou de a própria Administração, decidir que medida diferente da custeada pelo SUS deve ser fornecida a determinada pessoa que, por razões específicas do seu organismo, comprove que o tratamento fornecido não é eficaz no seu caso. (...) Situação diferente

é a que envolve a inexistência de tratamento na rede pública. Nesses casos, é preciso diferenciar os tratamentos puramente experimentais dos novos tratamentos ainda não testados pelo Sistema de Saúde brasileiro.

No Brasil a política pública de saúde é implementada, basicamente, através do SUS (Sistema Único de Saúde), o qual é normatizado pela Lei 8.080/90, cuja regulamentação se dá por diversos Decretos, donde se abstrai a disciplina jurídica relativa à lista Rename ${ }^{14}$, a qual, em síntese, representa a relação de todos os medicamentos e insumos incorporados ao SUS ${ }^{15}$, a serem disponibilizados graciosamente a todos os seus usuários, bastando que passem por um protocolo clínico, que pode ser desde a simples apresentação de receita médica e até mesmo a consulta por um médico da rede pública. 
Tal contexto, aliás, não é desconhecido do Judiciário, conforme se confere:

(a) A identificação dos protocolos clínicos do medicamento indicado, (b) a correta identificação da patologia, suas causas e histórico do paciente, (c) a indicação do princípio ativo do medicamento e sua eficiência científica ao tratamento proposto, (d) se é possível a indicação de medicamentos genéricos ou similares, justificando dentro de protocolos clínicos a negativa, (e) se o medicamento é importado ou se é produzido no País, com ou sem registro na Agência Nacional de Vigilância Sanitária (ANVISA) e, finalmente, (f) se o medicamento é de baixa, média ou alta complexidade. Tudo de modo justificado, com a manifestação do médico da parte, ressalvadas as informações realizadas no receituário ${ }^{16}$.

O Conselho Nacional de Justiça (CNJ), sobre essa temática, possui oito Enunciados $\operatorname{COMESC}^{17}$, os quais, ainda que verdadeiras diretrizes, merecem transcrição:

Enunciado 1 - As ações que versem sobre pedidos para que o Poder Público promova a dispensação de medicamentos ou tratamentos, fundamentadas no direito constitucional à saúde, devem ser instruídas com prescrição e relatório de médico em exercício no Sistema Único de Saúde, ressalvadas as hipóteses excepcionais, devidamente justificadas, sob risco de indeferimento de liminar ou antecipação da tutela.

Enunciado 2 - As prescrições médicas devem consignar o tratamento necessário ou medicamento indicado, contendo a sua Denominação Comum Brasileira (DCB) ou, na sua falta, a Denominação Comum Internacional (DCI), o seu princípio ativo, seguido, quando pertinente, do nome de referência da substância, posologia, modo de administração e período de tempo do tratamento $\mathrm{e}$, em caso de prescrição diversa daquela expressamente informada por seu fabricante, a justificativa técnica.

Enunciado 3 - Em caso de deferimento de liminar ou antecipação da tutela, é necessária a apresentação periódica do receituário médico, a cada três meses, ou em período menor, de acordo com a legislação sanitária, sob pena de revogação da medida.

\footnotetext{
${ }^{13}$ Disponível em http://www.stf.jus.br/portal/jurisprudencia/pesquisarJurisprudencia.asp. Acesso em 05.01.2016.

${ }^{14}$ Decreto no 7.508/11 - “art. 25. A Relação Nacional de Medicamentos Essenciais - RENAME compreende a seleção e a padronização de medicamentos indicados para atendimento de doenças ou de agravos no âmbito do SUS".

${ }^{15}$ Frise-se que, por se tratar de política pública voltada exatamente a beneficiar um maior número possível de pessoas, dentro de um orçamento limitado, o administrador acaba por ter que realizar um exame pormenorizado de quais medicamentos inserir nessa lista, cujos parâmetros, a grosso modo, representam um patamar razoável de eficácia necessária, em contrapartida ao valor do medicamento em si.

${ }^{16}$ Processo 1011219-02.2014.8.26.0196. Vara da Fazenda Pública da Comarca de Franca/SP. Disponível em www.tjsp.jus.br. Acesso em 03.01.2016.

17 Disponível em http://www.cnj.jus.br/atos-administrativos/atos-da-presidencia/resolucoespresidencia/455acoes-e-programas/programas-de-a-a-z/forum-da-saude/26634-enunciados-comesc. Acesso em 08.01.2016.
} 
Enunciado 4 - A determinação judicial de fornecimento de medicamentos deve observar a existência de registro na ANVISA.

Enunciado 5 - O Poder Judiciário deverá utilizar os critérios da Medicina Baseada em Evidências Científicas para decidir as demandas relacionadas às prestações de assistência à saúde, em especial quando se tratar de tecnologias (medicamentos, procedimentos, materiais etc) não incorporadas pelo Sistema.

Enunciado 6 - Ao impor a obrigação de prestação de saúde, o Poder Judiciário deve levar em consideração as competências das instâncias gestoras do SUS.

Enunciado 7 - A alegação de urgência e risco à vida deve ser corroborada por declaração de profissional da saúde, sob pena de desconsideração pelo juiz, salvo caso de comprovada impossibilidade.

Enunciado 8 - É necessária a apresentação de prova técnica fundamentada pela parte autora para instruir a inicial e, se houver, o pedido de tutela antecipada em ação ajuizada para obtenção de tratamento(s) medicamentos, procedimentos, insumos e/ou consultas médicas - não padronizado(s)/fornecido(s) pelo Sistema Único de Saúde-SUS, recomendando-se o uso de questionário formulado por este Comitê Executivo e outros disponibilizados no Portal da Saúde, no sítio da Corregedoria Geral de Justiça do Tribunal de Justiça de Santa Catarina, acessíveis através do endereço http://cgj.tjsc.jus.br/saude/index.htm.

Referidos enunciados, impõe reconhecer, denotam um reconhecimento da existência de política pública implementada, com protocolos tendentes ao fornecimento de medicamentos essenciais, eficazes e seguros, cuja leitura e consideração são de grande valia para que não haja um total desrespeito àquilo que o gestor público se propõe a fazer.

A própria doutrina já se debruçou sobre o assunto, a exemplo do hoje Ministro do STF, Luís Roberto Barroso, para quem alguns fatores devem ser levados em consideração, a exemplo do magistrado "ater-se a efetivar a dispensação dos medicamentos constantes das listas elaboradas pelos entes federativos" 18 (BARROSO, 2010), até mesmo porque, conforme pondera Barroso (2010) presume-se que Legislativo e Executivo, ao elaborarem as listas referidas, avaliaram, em primeiro lugar, as necessidades prioritárias a serem supridas e os recursos disponíveis, a partir da visão global que detêm de tais fenômenos. E, além disso, avaliaram também os aspectos técnico-médicos envolvidos na eficácia e emprego dos medicamentos.

Luís Roberto Barroso assim se posiciona sobre a matéria: 
a) O Judiciário só pode determinar a inclusão, em lista, de medicamentos de eficácia comprovada, excluindo-se os experimentais e os alternativos.

b) O Judiciário deverá optar por substâncias disponíveis no Brasil.

c) O Judiciário deverá optar pelo medicamento genérico, de menor custo.

d) O Judiciário deverá considerar se o medicamento é indispensável para a manutenção da vida ${ }^{19}$.

Impõe destacar ainda um dos principais - senão o principal - parâmetro a ser considerado nas demandas de medicamentos, que vem a ser exatamente a existência, ou não, de registro na Anvisa.

A Anvisa - Agência Nacional de Vigilância Sanitária - consiste numa Autarquia Federal, criada pela Lei $n^{\circ} 9.782 / 99$, com atuação voltada para todos os setores relacionados a produtos e serviços que possam afetar a saúde da população brasileira, sendo que, dentre suas competências, está a de "conceder registros" (art. $7^{\circ}$, IX), os quais são representativos de aprovação de eficácia e segurança do medicamento, tanto que somente após aprovado pela referida agência reguladora, é que o produto pode ser distribuído legalmente em território nacional.

Nesse sentido, a Lei 8.080/90, com alteração feita pela Lei 12.401/11, deixa expressa a vedação de fornecimento de medicamento não aprovado pela Anvisa, conforme se confere:

Art. 19-T. São vedados, em todas as esferas de gestão do SUS:

I - o pagamento, o ressarcimento ou o reembolso de medicamento, produto e procedimento clínico ou cirúrgico experimental, ou de uso não autorizado pela Agência Nacional de Vigilância Sanitária ANVISA;

II - a dispensação, o pagamento, o ressarcimento ou o reembolso de medicamento e produto, nacional ou importado, sem registro na Anvisa.

Outrossim, o CNJ, além do Enunciado COMESC n 4, já transcrito acima, editou a Recomendação $\mathrm{n}^{\mathrm{o}}$ 31, de 30 de março de 2010, pela qual é claro no seguinte sentido:

\footnotetext{
18 Disponível em http://www.migalhas.com.br/dePeso/16,MI52582,81042-

$\mathrm{Da}+\mathrm{falta}+\mathrm{de}+$ efetividade+a+judicializacao+excessiva+Direito+a+saude. Acesso em 09.01.2016.

19 Disponível em http://www.migalhas.com.br/dePeso/16,MI52582,81042-

$\mathrm{Da}+\mathrm{falta}+\mathrm{de}+$ efetividade+a+judicializacao+excessiva+Direito+a+saude. Acesso em 09.01.2016.
} 
b.2. evitem autorizar o fornecimento de medicamentos ainda não registrados pela ANVISA, ou em fase experimental, ressalvadas as exceções expressamente previstas em lei;

O Supremo Tribunal Federal, por sua vez, já se manifestou sobre o assunto:

[...] o registro na Anvisa mostra-se como condição necessária para atestar a segurança e o benefício do produto, sendo a primeira condição para que o Sistema Único de Saúde possa considerar sua incorporação (STF, STA 244/10, DOU 18.09.2010).

Inclusive, há pendente de julgamento - com repercussão geral reconhecida - os Recursos Extraordinários $n^{\circ}$ 657.718e 566.471, os quais versam exatamente sobre pedido de fornecimento de medicamento não registrado pela Anvisa.

De qualquer forma, inexistindo qualquer comprovação de eficácia terapêutica - e segurança - certificada pela Anvisa, tal substância sequer pode ser denominada de medicamento no território nacional, muito menos prescrita por um médico ou autorizada por um magistrado quanto ao seu fornecimento.

Este panorama político e jurídico, que culminou nas análises de decisões do Poder Judiciário em sede de determinar à Administração Pública o fornecimento de medicamentos, oferece-nos o arcabouço necessário para que possamos considerar especificamente o caso da nova substância denominada de fosfoetanolamina, o que passaremos a fazer em seguida.

\section{A FOSFOETANOLAMINA SINTÉTICA: UM CASO DE JUDICIALIZAÇÃO DE FORNECIMENTO DE MEDICAMENTOS}

Ao pesquisar a fosfoetanolamina, de plano visualiza-se reportagem com o seguinte título: "Fosfoetanolamina sintética: a oferta de um milagre contra o câncer" (BUSCATO, BUSCATO, RODRIGUES E FREITAS, 2015). O título da matéria já aponta para algo peculiar, sensacional e polêmico, haja vista a utilização do termo "milagre".

No Brasil, a fosfoetanolamina sintética tem como estudioso-referência o professor de química, hoje aposentado, Dr. Gilberto Orivaldo Chierice que, durante cerca de 20 (vinte) anos, esteve à frente da pesquisa pela Instituição de Química de São Carlos, da Universidade de São Paulo. 
Nesse ínterim, a fosfoetanolamina era fabricada e entregue de forma gratuita à população, até que em 2014 foi editada uma Portaria pelo Instituto de Química da Faculdade USP de São $\operatorname{Carlos}^{20}$, determinando a exigência de que quaisquer substâncias experimentais, para serem disponibilizadas à população, deveriam estar com todos os registros previamente regularizados. Logo, não estando a "fosfo" devidamente registrada nos órgãos competentes (Anvisa e Ministério da Saúde), restou cessado o seu fornecimento.

Há duas dissertações de mestrado apresentadas na USP de São Carlos no ano de 2007, com orientação pelo então professor Gilberto. A primeira, de Marcos Vinicius Almeida, intitulada "Aplicação pré-clínica da fosfoetanolamina sintética sobre modelos experimentais de epilepsias", de 2007. A segunda de Renato Meneguelo intitulada "Efeitos antiproliferativos e apoptóticos da fosfoetanolamina no melanoma B16F10”, de 2007, nas quais é possível visualizar a indicação de resultados promissores quanto ao uso dessa substância no combate a doenças como o câncer, com destaque para o fato de ter sido notada uma relação entre a ausência de fosfoetanolamina e os casos de surgimento de patologias e tumores, além dos próprios benefícios relatados quanto ao tratamento dessa doença de difícil cura.

Nada obstante, a Instituição de Pesquisa (IQCS), na qual se concentram os estudos dessa substância, pronunciou-se oficialmente no sentido de que a legislação pertinente, com destaque para a Lei $n^{\circ}$ 6.360/76, proíbe a produção e a distribuição de quaisquer substâncias medicamentosas sem as devidas licenças e registros expedidos pelos órgãos competentes (Anvisa e Ministério da Saúde), abrangendo, pois, o caso da fosfoetanolamina sintética.

Por sua vez, a Anvisa também cuidou de se manifestar, pontuando que "para que um medicamento venha a ser registrado e comercializado, é necessário que a Anvisa avalie a documentação administrativa e técnico-científica relacionada à qualidade, à segurança e à eficácia do medicamento" ${ }^{21}$, sendo que, especificando o caso, esclarece que "não há em curso qualquer avaliação de projetos contendo a fosfoetanolamina para fins de pesquisa clínicas envolvendo seres humanos", destacando o próprio risco que essa substância gera, uma vez que "o uso da fosfoetanolamina pode favorecer o abandono de tratamentos prescritos pela medicina tradicional, os quais podem beneficiar ou curar a doença".

20 Portaria IQSC (Instituto de Química de São Carlos) no 1389/2014. Disponível em http://www5.iqsc.usp.br/esclarecimentos-a-sociedade/. Acesso em 22 de janeiro de 2.016.

${ }^{21}$ Nota técnica no 56/2015/SUMED/ANVISA. Acessível em http://portal.anvisa.gov.br. 
Desse contexto, evidencia-se a ausência de qualquer reconhecimento oficial quanto à eficácia e segurança desta substância ${ }^{22}$, em que pese existam poucos estudos técnicos indicando a relação com o câncer, e mais, com resultados positivos de sua utilização ${ }^{23}$.

Diante do impasse surgido, devidamente segmentado pela proibição administrativa de fornecer a substância, resultado não foi outro senão o encaminhamento do debate ao Judiciário, onde a discussão passou a ser travada.

O Tribunal de Justiça do Estado de São Paulo, num primeiro momento, foi cauteloso e não deferiu os requerimentos que lhes foram apresentados, tanto que, ante a existência de algumas liminares concedidas em juízos singulares de primeiro grau, a Corte Paulista acolheu o pedido de suspensão formulada pela USP (autos $\mathrm{n}^{\circ} 2194962-67.2015 .8 .26 .0000$ ), no qual, $a$ priori, deferiu-se a tutela antecipada, suspendendo todas as liminares concedidas. Porém, em sequência, o Presidente do Tribunal Paulista indeferiu o pedido da Autarquia educacional, restando mantidas, por consequência, as liminares dos juízes de primeira instância.

Não se conformando, a USP apresentou recurso de agravo interno, direcionando-se ao Órgão Especial do Tribunal de Justiça, requerendo a reconsideração da decisão proferida pelo então presidente do Tribunal, o que acabou sendo acolhido por aquele órgão distinto, e, por conseguinte, consolidando o entendimento na jurisprudência paulista ${ }^{24}$, no sentido de não acolhimento, ao menos em sede de antecipação dos efeitos da tutela, do pedido de fornecimento da substância.

Em paralelo, a discussão foi levada ao Supremo Tribunal Federal, pois a paciente postulante, quando foi dada a tutela antecipada no pedido de suspensão, correu a buscar socorro à Suprema Corte, por meio da Petição n ${ }^{\circ} 5.828$ MC/SP. Nestes autos, recebidos pelo Ministro Luiz Edson Fachin, foi dado um primeiro provimento, determinando o fornecimento da substância - com o afastamento preliminar da decisão do TJ/SP que ordenava a suspensão dos fornecimentos.

\footnotetext{
${ }^{22}$ Não se pode esquecer - e muito menos menosprezar - que o registro junto à Anvisa representa o ato final de todo um procedimento investigativo pormenorizado e complexo, que, quando finalizado, traduz a certificação de que a substância - com caráter de medicamento - seja realmente eficaz e segura para a saúde do paciente.

${ }^{23}$ Frise-se que em nota pública lançada pelo Conselho Regional de Farmácia de Santa Catarina (Autarquia Pública Federal), foram divulgadas diversas irregularidades quanto às cápsulas milagreiras (peso, dosagem e etc.), e, ainda, que dentre várias substâncias ali existentes, tão apenas uma demonstrou potencial antitumoral, mas a magnitude é inferior às substâncias já disponíveis no mercado. Disponível em http://crfsc.gov.br/fosfoetanolamina-testesiniciais-apontam-baixo-potencial-contra-tumor/. Acesso em 13 de janeiro de 2.016.
} 
Nada obstante, com o transcurso do pedido de suspensão no TJ/SP, inclusive com o deslinde já mencionado, essa Petição no 5.828 acabou sendo extinta sem resolução de mérito, pela falta superveniente de interesse. In verbis:

Assim, a causa de pedir que fundamentou a interposição do presente recurso não mais subsiste, razão pela qual, nos termos do art. 267, VI, do Código de Processo Civil (falta de interesse de agir superveniente), há que se reconhecer a perda de objeto da presente cautelar. Pelo exposto, julgo extinta, sem julgamento de mérito, a presente ação e prejudicados os pedidos de ingresso e de reconsideração.

Recentemente, no pedido de Suspensão de Tutela Antecipada (STA) nº 828 formulado pela USP ${ }^{25}$, o Ministro Ricardo Lewandowski acolheu a pretensão da Universidade, de forma a suspender aquela liminar deferida, e, indo além, pontuou que a Entidade mantenha o fornecimento da substância tão apenas aos casos pretéritos já deferidos, porém, também, tão apenas enquanto houver estoque da referida substância ${ }^{26}$.

O seguinte trecho noticiado bem sintetiza os fundamentos da decisão:

O ministro Ricardo Lewandowski ressaltou que "a inexistência de estudos científicos que atestem que o consumo da fosfoetanolamina sintética seja inofensivo ao organismo humano" e o desvio de finalidade da instituição de ensino, que tem como atribuição promover a educação, são justificativas à suspensão de seu fornecimento pela USP, após o término do estoque já existente. ${ }^{27}$

No âmbito do Superior Tribunal de Justiça há um caso específico envolvendo a "fosfo" $\left(\mathrm{MC} \mathrm{n}^{\circ} 25.285 / \mathrm{SP}\right)$, em que, verdadeiramente, não houve um efetivo posicionamento a respeito da matéria, uma vez que tão apenas apreciou uma pretensão cautelar que buscava efeito suspensivo a recurso especial interposto ${ }^{28}$.

\footnotetext{
${ }^{24}$ Procurando pela expressão "fosfoetanolamina" junto ao site do TJ/SP (pesquisa de jurisprudência), obtém-se o resultado de 1.057 acórdãos proferidos, além de 62 decisões monocráticas.

${ }^{25}$ Decisão monocrática publicada no DJE do dia 07/04/2016. STA manuseado em face de tutela antecipada concedida no Agravo de Instrumento 2242691-89.2015.8.26.0000, em trâmite perante a $11^{\text {a }}$ Câmara de Direito Público do Tribunal de Justiça do Estado de São Paulo.

${ }^{26}$ Vale pontuar que o laboratório onde era fabricada a substância foi fechado pela Universidade, conforme noticiado. Disponível em http://g1.globo.com/sp/sao-carlos-regiao/noticia/2016/04/usp-manda-lacrar-laboratoriode-sao-carlos-que-produz-fosfoetanolamina.html.

27 Disponível em http://www.stf.jus.br/portal/cms/verNoticiaDetalhe.asp?idConteudo=313641. Acesso em 08/04/2016.
} 
Dessa maneira, basicamente é esse o quadro das demandas judiciais envolvendo pedidos de fosfoetanolamina na jurisprudência, frisando que, a despeito do entendimento firme já sinalizado pelo TJ/SP, e, a despeito do STJ não ter assumido uma posição firme e sólida a respeito do assunto, o STF, na figura do seu então presidente - o Ministro Ricardo Lewandowski - pontuou claramente a impossibilidade de se determinar o fornecimento da substância, caminhando para o encerramento da discussão sobre esse caso em específico.

\section{CONSIDERAÇÕES FINAIS}

Do que se analisou, não se discute a sindicabilidade judicial dos direitos sociais, sendo que, argumentos tais como separação dos poderes, reserva do possível, discricionariedade de políticas públicas, dentre outros, não tem sido vistos como suficientes para inibir um pedido de fornecimento de medicamento perante o Judiciário.

Contudo, a situação é peculiar quando o medicamento (ou substância) pleiteado em juízo não possui registro na Anvisa, isto é, não possui, perante à autoridade nacional competente, comprovação da eficácia terapêutica da substância, bem como da segurança à saúde de quem fizer uso.

Em casos desta natureza é possível visualizar na Legislação pertinente expressa vedação de circulação dessas substâncias, recomendação do CNJ no mesmo sentido, pronunciamento do STF, a despeito de estar pendente de recursos com repercussão geral reconhecida e, por fim, a doutrina também já se manifestou pela impossibilidade de se impor fornecimento de medicamento não registrado na Anvisa.

\footnotetext{
${ }^{28}$ In casu, o juiz de primeira instância deferiu a tutela antecipada, determinando que Estado de São Paulo e USP (pessoas jurídicas distintas) forneçam, $a b$ initio,a substância, sendo que, inconformado o Estado interpôs agravo de instrumento, tendo obtido êxito.Por assim ter sido, a paciente manuseou recurso especial dessa decisão (ainda não julgado) e, em sequência, ajuizado a medida cautelar mencionada, visando obter efeito suspensivo ao recurso especial interposto. Contudo, o Ministro relator Sérgio Kukina negou seguimento à medida cautelar pontuando que o fornecimento da substância estaria preservado (sem problema de interrupção), eis que tão apenas o Estado de São Paulo insurgiu-se especificamente contra a referida decisão, que, naquele momento, valia plenamente em detrimento da USP. Em outros termos, face à falta de efetiva repercussão prática (fornecimento ou não da substância), o STJ não se inseriu - pelo menos até o momento - na discussão.
} 
No último dia 07 de abril de 2016 o Ministro Ricardo Lewandowski, tratando do caso da fosfoetanolamina, pontuou que, embora o Judiciário esteja sempre sensibilizado com as demandas de medicamentos, "não caberia ao Poder Judiciário respaldar a prática de uma medicina não baseada em evidências", sendo que, na hipótese dessa substância, ainda não teve o seu ciclo de estudos concluído, sendo desconhecida sua segurança e eficácia terapêutica tanto no Brasil como no exterior. Logo, reconhece o Ministro do STF que a impossibilidade de se determinar o fornecimento dessa "substância química".

Assim, caso um magistrado acolha um pedido de fornecimento da fosfoetanolamina sintética, estará se contrapondo ao conhecimento científico existente sobre a neoplasia maligna, e também da substância em si, bem como contrariando decisão da Suprema Corte, tendo em vista que a decisão do Ministro Ricardo Lewandowisk determina a suspensão da tutela antecipada concedida pela $11^{\mathrm{a}}$ Câmara de Direito Público do Tribunal de Justiça do Estado de São Paulo, bem como de todas as decisões judiciais, indicadas ou não nos autos, que tenham determinado à Universidade de São Paulo o fornecimento da substância "fosfoetanolamina sintéticas" para tratamento de câncer".

Portanto, diante das peculiaridades que envolvem a fosfoetanolamina sintética, em especial a ausência de conhecimento da eficácia terapêutica e de eventual risco à saúde do paciente, sem, ainda, a competente certificação pela Anvisa, não é razoável que os tribunais defiram semelhantes pedidos, embasados simplesmente na esperança infundada de cura de câncer, não sendo possível (factível e juridicamente) concordar com uma busca incondicionada e irrazoável.

É mister que se afirme que a atuação do Poder Judiciário deve se orientar segundo as regras previamente definidas, e na ausência destas, pelos princípios. Não cabe ao juiz agir como legislador, orientando-se de forma finalística pelos interesses da coletividade, o que é próprio do político.

Conclui-se, portanto, que, na ausência de regulamentação da substância em comento, não cabe ao Poder Judiciário decidir de forma a obrigar o Administrador Público a fornecê-la, o que afetaria o princípio da razoabilidade jurídica. 


\section{REFERÊNCIAS}

ABBOUD, Georges. Discricionariedade administrativa e judicial. São Paulo: Revista dos Tribunais, 2014.

AGRA, Walber Moura. Direitos Sociais. In: coord.: MARTINS, Ives Gandra da Silva, MENDES, Gilmar Ferreira, NASCIMENTO, Carlos Valder do. Tratado de direito constitucional. São Paulo: Saraiva, 2010. Págs. 510-554.

ALMEIDA, Marcos Vinicius. Aplicação pré-clínica da fosfoetanolamina sintética sobre modelos experimentais de epilepsias. 2007. 60 f. dissertação (mestrado: Escola Engenharia de São Carlos, Faculdade de Medicina de Ribeirão Preto e Instituição de Química de São Carlos da Universidade de São Paulo), 2007.

BARCELLOS, Ana Paula de. A eficácia jurídica dos princípios constitucionais: o princípio da dignidade da pessoa humana. $3^{\mathrm{a}}$ ed. Rio de Janeiro: Renovar, 2011.

BARROSO, Luís Roberto. Da falta de efetividade à judicialização excessiva: direito à saúde, fornecimento gratuito de medicamento e parâmetros para a atuação judicial. In: NETO, Cláudio de Souza; SARMENTO, Daniel (coord.). Direitos Sociais: fundamentos, judicialização e direitos sociais em espécie. Rio de Janeiro: Lumen Juris, 2010.

BUCCI, Maria de Paula Dallari. Direito administrativo e políticas públicas. São Paulo: Saraiva, 2002.

BUCCI, Maria Paula Dallari. Constitucionalização das políticas públicas em matéria de direitos fundamentais: o controle político-social e o controle jurídico no espaço democrático. In: SARLET, Ingo Wolfgang e TIMM, Luciano Beneti. Direitos Fundamentais: Orçamento e “Reserva do Possível”. Porto Alegre: Livraria do Advogado, 2008.

BUSCATO, Marcela; RODRIGUES, Ana Helena; FREITAS, Ariane. Fosfoetanolamina Sintética: a oferta de um milagre contra o câncer. Revista Época, outubro de 2.015. Disponível em http://epoca.globo.com/vida/noticia/2015/10/fosfoetanolamina-sintetica-oferta-de-ummilagre-contra-o-cancer.html. Acesso em 20.01.2016.

CAMBICROLI, Fabiana. Ações na Justiça de São Paulo por Tratamentos e Medicamentos sobem 32\% em 3 anos. Jornal "O Estado de São Paulo”, 11 de janeiro de 2.015. Disponível em 
http://saude.estadao.com.br/noticias/geral,acoes-na-justica-de-sp-por-tratamentos-emedicamentos-sobem-32-em-3-anos,1618519. Acesso em 20 de janeiro de 2.016.

CANELLA JÚNIOR, Osvaldo. O. Controle judicial de políticas públicas. São Paulo: Saraiva, 2001 .

COMPARATO, Fábio Konder. Ensaio sobre o juízo de constitucionalidade de políticas públicas. Brasília: Revista de Informação Legislativa. Ano 35 n. 138 abr./jun. 1998. Págs. 3948.

DWORKIN, Ronald. Levando os Direitos a Sério. São Paulo: Martins Fontes, 2002. FALSARELLA, Christiane. Reserva do possível como aquilo que é razoável se exigir do Estado. Associação dos procuradores do Estado de São Paulo. São Paulo (SP), 2012. Disponível em http://www.apesp.org.br/comunicados/images/tese_christiane_mina_out2012.pdf). Acesso em 10.01.2016.

MELlO, Celso Antônio Bandeira de. Curso de Direito administrativo. 22a ed. São Paulo: Malheiros, 2007.

MENEGUELO, Renato. Efeitos antiproliferativos e apoptóticos da fosfoetanolamina no melanoma B16F10. 2007. dissertação (mestrado: Escola Engenharia de São Carlos, Faculdade de Medicina de Ribeirão Preto e Instituição de Química de São Carlos da Universidade de São Paulo), 2007.

MINISTÉRIO DA SAÚDE. Política nacional de plantas medicinais e fitoterápicos. Brasília, 2006.

PERRIN, Fernanda. Saúde vai ficar pior do que está, diz secretário do Estado de São Paulo. Jornal "Folha de São Paulo", 12/05/2015. Disponível em http://www1.folha.uol.com.br/seminariosfolha/2015/05/1627875-sistema-de-saude-vai-ficarpior-do-que-esta-diz-secretario-do-estado-de-sp.shtml. Acesso em 15.01.2016.

RAMOS, Elival da Silva. Ativismo Judicial: parâmetros dogmáticos. São Paulo: Saraiva, 2010.

SALLES, Carlos Alberto de. Políticas Públicas e Processo: a questão da legitimidade nas ações coletivas. In: org.: BUCCI, Maria Paula Dallari. Políticas Públicas: reflexões sobre o conceito 
jurídico. São Paulo: Saraiva, 2006. Pág. 177-191. Tal como mencionado pelo autor, o "Estado torna-se um implementador de políticas públicas".

SARLET, Ingo Wolfgang, FIGUEIREDO, Mariana Filchtiner. Reserva do possível, mínimo existencial e direito à saúde: algumas aproximações. Revista de Direitos Fundamentais e Justiça, no 1, 2007. Págs. 171-213.

SCHMIDT, João Pedro. Para entender as políticas públicas: aspectos conceituais e metodológicos. In: org. REIS, José Renato dos, LEAL, Rogério Gesta. Direitos sociais e políticas públicas: desafios contemporâneos. Tomo 8. Santa Cruz do Sul: Edunisc, 2008. Páginas 2307-2333.

SILVA, José Afonso da. Curso de direito constitucional positivo. 24 ed. São Paulo: Malheiros, 2005 .

TORRES. Ricardo Lobo. O mínimo existencial e os Direitos Fundamentais. In: Revista de Direito Administrativo, $\mathrm{n}^{\circ}$ 177, 1989. Págs. 20-49. 